\title{
A different stance in psychotherapeutic work: being unobtrusive in psychodynamic work with addicted patients a clinical review
}

\begin{abstract}
As a tribute to the work of Robert Grossmark on the unobtrusive stance in psychodynamic work with patients, this paper looks at the idea of exploring an unobtrusive therapeutic stance with particular focus in the setting on an addiction treatment center. It intends to shed more light in the understanding of how dynamics can unfold in new and novel ways that require the therapist to, from time to time, resist temptations to intervene in old, familiar approaches and dwell into the unfamiliar territory of being unobtrusive. It draws heavily from Grossmark's1 idea and clinical experience about the therapeutic value of a therapist taking an unobtrusive stance and resisting the temptation of prematurely providing analytical inputs, possibly disrupting an opportunity for the patients to make sense of and do deeper work with his/ her own materials. Some clinical vignettes will be explored in this paper through the lens of adopting the above stance.
\end{abstract}

Keywords: addiction, alcoholic, gamblers, therapist, analyze, feeling, symptoms
Volume 3 Issue 5 - 2017

\author{
Lawrence Tan \\ Institute of Mental Health, Singapore
}

Correspondence: Lawrence Tan, Institute of Mental Health, Buangkok Green Medical Park, I 0 Buangkok View, S (539747), Singapore, Tel +65964673 I3, Fax +6563892388, Email Kok_Kah_Tan@imh.com.sg

Received: April 28, 2017| Published: June 02, 2017

\section{Introduction}

Schermer ${ }^{2}$ posited that a skillful relational therapist needs to move adeptly and flexibly between the position of the detached analyst that maintains professional distance and the role of someone who could also be influenced by the actions and vibes other members bring into the group. The stance taken by the unobtrusive relational therapist seems to fall nicely between the 2 stances mentioned above. As Balint ${ }^{3}$ describes, sometimes in order to be healing to patients, there is a need to recognize and be with the patient and also to be unobtrusive and ordinary. It appears to me that the ability for the therapist to sometimes hold back and curb his/her tendencies to be analytical and interpretative can interestingly provide a climate that encourages the emergence and unfolding of the most "primitive" parts of the patient's functioning and his damaged way of being in the world. This was concretely exemplified with Gorssmark's ${ }^{1}$ work with Kyle where he initially struggled and attempted to

a. Make sense of Kyle's seemingly incoherent narratives about himself and his family.

b. Find a subject or a focus to anchor their therapy.

c. Set limits when Kyle "sauntered" in and out of therapy on his own terms almost bringing about an abrupt end to the treatment they had. It was interesting how Grossmark ${ }^{1}$ then came to realize (in contrary to what was typically sensible in a relational therapeutic relationship, i.e. attempting to get him to examine and "talk about" his role in a repetition of unbearable trauma) the value of allowing himself to flow with Kyle and freeing his futile attempts to organize and makes sense of the material that Kyle was verbalizing. It was also intriguing to note that the therapy began to take a turn from there with Kyle beginning to "analyze" and make sense of his own material and even verbalizing at times that he seemed to be getting things together, finding his own way. It was truly amazing how by entering those conversations with Kyle as just himself (possibly the therapist Kyle wanted him to be) and not the person wearing the therapist hat (plausibly the therapist he thinks he ought to be), letting go of his need to analyze, have a "good therapeutic session" and to "resolve enactments", Grossman ${ }^{1}$ began to see improvements in Kyle.

\section{Discussion}

It is important to note that the clinical vignettes (involving a few patients) discussed below are a composite of many cases seen over the years to

a. Dramatize and intensify the clinical situation to better explain and describe the therapeutic processes and unfolding of pathology.

b. Protect and disguise the identity of the patients discussed.

\section{On an individual level}

This stands out a lot for me as I recalled 2 patients (one in an individual therapy setting and the other in a group setting) I have seen some years ago. The first patient $\mathrm{L}$ is a young man struggling with alcoholism. His life was very much characterized by conflicts

a. His job required him to design brochures and public education material to promote responsible drinking but he was a "closet alcoholic".

b. His mother is a perfectionist, staunch Christian and patient has been struggling for the longest time with getting acceptance his homosexuality.

c. Feeling grateful to his mother for raising him single-handedly but repelled by her tendencies to be hypercritical towards him. For a while in therapy, this patient verbalized the deep sense of loneliness and isolation and that nobody could understand 
and connect with him on a deep level given that fact that he lived a "double-life" on so many dimensions in his world. There seems to be some similarities between Kyle and L (on different levels) where it can get frustrating in a session to pin him down and get engage him on a level I needed to engage him on.

As I work in an addiction treatment center, the bulk of the work is about addressing the addictive disorder and ways to manage and alleviate the symptoms. L, and as suggested by Winnicot, ${ }^{4}$ would often engage me in a conversation that did not appear to be anything like analysis or therapy. It could be anything from his fights with his brother when he was a boy, the crush he had on his teachers to his female boss's broken marriage and although not as extreme and chaotic as Kyle's narratives, it was nevertheless difficult to "get him to do the therapy talk". His resistance will be subtle but obvious at the same time; he would linger around in my room for at least half an hour after session, insisting that he had to "finish his piece" and if I were to interrupt him in between session and ask him if any of material he has presented has anything to do with his recovery. One incident that really stands out to me however, was a "casual" discussion about the death of his mother and how there was this sense of unfinished business with her (L's mother died within a month after she received news of having cancer). I mentioned how I felt his grief and how difficult it must have been for him to live with so many unanswered questions and unresolved issues all these years. The next day, I got an email from $L$ thanking me for sharing with him the death of my own mother and that he felt most deeply connected to me in at that moment as compared to many other points in my therapy with him. At that point, I was tempted to leave that as it is (since it appeared helpful) but decided not to lay claim to an experience (especially when it is potentially so deep and connecting to the patient) that I do not rightfully own.

In our next session, I told L I am glad he felt connected with me, clarified and told him my mother is still alive and that I do not want to pretend to own an experience that I do not have. Interestingly $\mathrm{L}$ in response told me that he must have imagined the whole episode and apologized profusely for it. What is even more fascinating for me was at the end of the session, L actually remarked that it must be his deep yearning for connection and his perpetual feelings of loneliness that drove him to the brink of desperation; to a point where he is even imagining things that are no there so that he could feel more connected and in touch. On hindsight, it is so interesting to note that I was dangerously close to destroying an opportunity for $\mathrm{L}$ to make sense of his regression should I, in any way, attempted to make sense of his "making up of the death of my mother".

\section{On a group level}

On a group level, I remembered this particular incident where I was running a group with a bunch of help-seeking gamblers. It was the beginning of the group and as we are about to get started, the wife of a relatively new member Jack barged in and started to expressing her disappointment with me as a facilitator for not translating the "goingons" in the group properly to his husband (who was not well versed in English) which subsequently resulted in him learning and benefitting little from the group. As soon as she finished her lashing out at me, she left the room before anyone could respond. What happened next was this mass attack of almost every member in the group on Jack. One member, Linda started talking about how Jack was being unfair to the group and me because the group made efforts to help him understand what was going on in the last session and he has responded and engaged with the group well. Another member, Anthony called Jack a dirty and disgusting liar just like a typical gambler. Jason added on to Anthony's remark and asked Jack to introduce himself not only as a pathological gambler but also a pathological liar in future sessions. This went on for a few minutes (for some reason I did not intervene, on hindsight maybe I was angry with Jack too and in my own ways, wanted him to be "punished" by the group) and the conversation then (interestingly) shifted inwards for some members who began to indicate how they could relate to Jack on a different level. They talked about seeing parts of themselves in him, the fear and anxiety of cutting away from something they are so familiar with, the tendency to go to any extent to "protect" something that is causing them so much harm and the kind of "wild goose chase" which they often made their family members go through when they are unable to see the problem within themselves.

On hindsight, looking at the group processes in the spirit and lens of intersubjective relational work, the phenomenon of scapegoating is rather apparent. There was an attack, by almost all the group members on an elected member, when the group attempted to establish a safe place for the majority or the "norm' by the distancing of "outsiders" that doesn't belong. ${ }^{5}$ The group was, intriguingly, also able to engage in their own process of "reclaiming the projections" from Jack and in their own ways, recognized that there were split off and disowned parts of themselves that they have projected onto Jack. I would agree that if this process is somewhat interrupted by the therapist, the regression from the group members may not unfold in its full glory and be made available for work in the group. This also reminded of a zoom session with Dr Grossmark where he talked about how when you take the stance of an unobtrusive group analyst, you sometimes allow members to "act out" and "talk to one another" through their stories, make sense of their regressions and at some point help one another "become their own analyst", facilitating the process of healing. The process of enactment was very obvious in that group as Jack (through his actions and ways of being but not through "sayable" narratives) in his own ways brought the group into "unfamiliar territories" of dissociated trauma that they have yet to fully experience and have them activated in the group enactment. ${ }^{6}$ I was amazed to find similarities between how George apologize to Susan about his intrusive question, relating back to his own legacy of incest in his household ${ }^{6}$ and in my situation, how group members responded to Jack by being initially angry and disgusted with him and then relating these strong feelings back to a time when they were struggling with similar shame, guilt and denial about their addictive behaviours.

\section{About dreams}

I was also fascinated by the part where Grossmark ${ }^{6}$ had a dream of Susan on fire and the idea that a burnt victim symbolically represented her. I remembered not too long after reading the paper, there was a case discussion in my clinical department of a 40 year old man who struggled with compulsive sexually behaviour. He was interviewed in person by the team and it seemed like, on a superficial level, he does not appear to struggle with any other complex co-morbidity or personality disorders but just cannot seem to manage his impulses to seek out the services of commercial sex workers despite negative social consequences. This activity would carry on even to the detriment of his finances, social life, martial life and career. Later that night, I had a dream of this man as a boy attending elementary school. In my dream, he did something wrong and was asked to stand in a corner of the class. After the class ended, the teacher dismissed all the students and 
while she was alone with the patient, she began to touch him rather inappropriately. It was clear in my dream that he was feeling disturbed but stuck at the same time. He seemed to be behaving as if he deserved the punishment although it was making him terribly uncomfortable. It was a rather disturbing dream and it set me thinking it this has any connection with the patient's life and struggles which may be, for many reasons undisclosed, unavailable or as Grossmark ${ }^{6}$ mentioned, "unsayable". Was there something about his demeanor, his way of being in the clinical interview that somewhat opens a little doorway to the inner world of dissociated trauma that he is not communicating about in words and was so powerful that it manifested in my dreams? Could this be, in any way, an indication or a symbolic representation of the pain and abuse he may have experienced as a child or could this be a snapshot of the emotional and mental states in the moment when he was interviewed (stuck, embarrassed, molested, intruded upon, etc) and in what way would that connect us to his way of being with other people in his life. ${ }^{7,8}$

\section{Conclusion}

The works of Grossmark (2012/2016) and Schermer (2010) were refreshing to me as a therapist doing both individual and group psychotherapy with patients struggling with addictive behaviours. It is especially enlightening in the field of addictions where doctors, therapists and case workers struggle so intensely with the instinct to "correct", "analyze", "reframe" and "psycho-educate" instead of freeing these addicted patients from their "sick-role" to make sense of their own chaos and to narrate what was previously unsayable to them leading to deeper therapeutic changes. Writing this paper was an enlightening experience as it brought back many memories of my patients and how I had the opportunity to re-look at my psychotherapeutic sessions and the processes that were going on at that point in a whole new light all together. The question of when to intervene remains a difficult one as there were indeed some instances where intervention appeared crucial and others where being unobtrusive allowed the "magic" between members and their stories to beautifully unfold. Looking back and reflecting on the many clinical transactions I have experienced with patients over the last decade, I realize that many a times (although I am not necessarily always acutely aware) members will tell you, in their own ways, when is the time to take a step back and allow them to analyze, interpret and make sense of their own "chaos" and when is the time to step in and be the analyst they needed (and not the analyst I wanted to be).

\section{Acknowledgements}

Charles Mak, Guo Song, Robert Grossmark.

\section{Conflict of interest}

The author declares no conflict of interest.

\section{References}

1. Robert Grossmark. The Unobtrusive Relational Analyst. Psychoanalytic Dialogues. 2012;22(6):629-646.

2. Schermer VL. Mirror Neurons: Their Implications for Group Psychotherapy. Int J Group Psychother. 2010;60(4):486-513.

3. Michael Balint. The basic fault. London, UK: Tavistock; 1979. 205 p.

4. Winnicott DW The capacity to be alone. In: DW Winnicott, editor. The maturation processes and the facilitating environment. London, UK: Karnac Books; 1958. p. 29-36.

5. Robi Friedman. Where to look? Supervising Group Analysis - A Relations Disorder Perspective. Group Analysis. 2007;40(2):251-268.

6. Robert Grossmark. Narrating the unsayable: Enactment, Repair, and Creative Multiplicity in Group Psychotherapy. International Journal of group psychotherapy. 2016;67(1):27-46.

7. Louis Zinkin. Malignant mirroring. Group Analysis. 1983;16(2):113126.

8. Louis Zinkin. Borderline distortions of mirroring in the group. Group analysis. 1992;25(1):27-31. 